\title{
Evaluation of a genomic classifier in radical prostatectomy patients with lymph node metastasis
}

\author{
Hak J Lee' \\ Kasra Yousefi ${ }^{2}$ \\ Zaid Haddad ${ }^{2}$ \\ Firas Abdollah ${ }^{3}$ \\ Lucia LC Lam² \\ Heesun Shin ${ }^{2}$ \\ Mohammed Alshalalfa ${ }^{2}$ \\ Elana Godebu' \\ Song Wang ${ }^{4}$ \\ Ahmed Shabaik ${ }^{5}$ \\ Elai Davicioni ${ }^{2}$ \\ Christopher J Kane' \\ 'Department of Urology, University \\ of California, San Diego, San Diego, \\ CA, USA; ${ }^{2}$ GenomeDx Biosciences \\ Inc., Vancouver, BC, Canada; ${ }^{3}$ Vattikuti \\ Urology Institute, Henry Ford \\ Hospital, Detroit, MI, ${ }^{4}$ UC San Diego \\ Health System, San Diego, CA, \\ ${ }^{5}$ Department of Pathology, University \\ of California, San Diego, San Diego, \\ CA, USA
}

This article was published in the following Dove Press journal:

Research and Reports in Urology

28 June 2016

Number of times this article has been viewed

Objective: To evaluate the performance of the Decipher test in predicting lymph node invasion (LNI) on radical prostatectomy (RP) specimens.

Methods: We identified 1,987 consecutive patients with RP who received the Decipher test between February and August 2015 (contemporary cohort). In the contemporary cohort, only the Decipher score from RP specimens was available for analysis. In addition, we identified a consecutive cohort of patients treated with RP between 2006 and 2012 at the University of California, San Diego, with LNI upon pathologic examination (retrospective cohort). The retrospective cohort yielded seven, 22, and 18 tissue specimens from prostate biopsy, RP, and lymph nodes (LNs) for individual patients, respectively. Univariable and multivariable logistic regression analyses were used to evaluate the performance of Decipher in the contemporary cohort with LNI as the endpoint. In the retrospective cohort, concordance of risk groups was assessed using validated cut-points for low $(<0.45)$, intermediate $(0.45-0.60)$, and high $(>0.60)$ Decipher scores.

Results: In the contemporary cohort, $51(2.6 \%)$ patients had LNI. Decipher had an odds ratio of 1.73 (95\% confidence interval, 1.46-2.05) and 1.42 (95\% confidence interval, 1.19-1.7) per $10 \%$ increase in score on univariable and multivariable (adjusting for pathologic Gleason score, extraprostatic extension, and seminal vesicle invasion), respectively. No significant difference in the clinical and pathologic characteristics between the $\mathrm{LN}$ positive patients of contemporary and retrospective cohorts was observed (all $P>0.05$ ). Accordingly, among LN-positive patients in the contemporary cohort and retrospective cohort, $80 \%$ and $77 \%$ had Decipher high risk scores $(P=1)$. In the retrospective cohort, prostate biopsy cores with the highest Gleason grade and percentage of tumor involvement had 86\% Decipher risk concordance with both RP and LN specimens.

Conclusion: Decipher scores were highly concordant between pre- and post-surgical specimens. Further, Decipher scores from RP tissue were predictive of LNI at RP. If validated in a larger cohort of prostate biopsy specimens for prediction of adverse pathology at RP, Decipher may be useful for improved pre-operative staging.

Keywords: prostate, biopsy, lymph node invasion, genomic classifier, radical prostatectomy, decipher, prognosis

\section{Introduction}

Recently, development of genomic signatures in prostate cancer has improved our understanding of disease biology. ${ }^{1,2}$ Decipher ${ }^{\circledR}$ represents one such test that was developed to predict disease progression after radical prostatectomy (RP) in a cohort of 359 patients. $^{3}$ Since its conception, Decipher has been validated in multiple cohorts with varying levels of risk and patient populations. ${ }^{4-13}$ In a majority of previous studies, Decipher was performed using formalin-fixed paraffin embedded specimens from whole gland pathol-
Correspondence: Christopher J Kane Department of Urology, University of California, San Diego, 3855 Health Sciences Drive, MC0987, La Jolla CA 92093-0987 San Diego, CA, USA
Research and Reports in Urology 2016:8 77-84

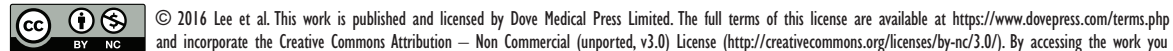

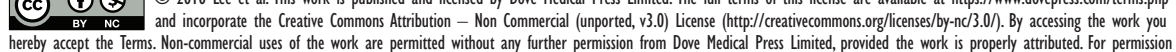
hereby accept the Terms. Non-commercial uses of the work are permitted without any further permission from Dove Medil
for commercial use of this work, please see paragraphs 4.2 and 5 of our Terms (https://wwr.dovepress.com/terms.php).
Dovepress

http://dx.doi.org/1 0.2147/RRU.S99997 
ogy. ${ }^{4-13}$ Only recently, performance and feasibility of Decipher on prostate biopsy (PBx) specimens have been studied. ${ }^{10}$ In the present study, we set to: 1) determine the agreement of Decipher among matched PBx, RP, and lymph node (LN) pathologic specimens from individual patients and 2) evaluate the performance of the Decipher genomic classifier in predicting lymph node invasion (LNI) on RP specimens.

\section{Materials and methods}

\section{Patient cohorts}

We identified 1,987 consecutive patients with RP who received the Decipher test between February 1 and August 1, 2015, from 308 centers. This contemporary cohort was deidentified, and study researchers were blinded to patient identities and had no access to personally identifiable health information (ClinicalTrials.gov number, NCT02609269). The Qurorum Institutional Review Board (record number: 31079) approved the research protocol for this study. Since all patient related data was de-identified and study researchers were blinded to patient identities and did not have access to personally identifiable health information, it was exempt from human subjects review, and members of the study population did not have to provide informed consent. In the contemporary cohort, only the Decipher score from RP specimens was available for analysis.

The retrospective cohort consisted of 25 consecutive patients treated with RP between 2006 and 2012 with pathologically determined LN metastases (LNI) and available tissue blocks and clinical data at the University of California, San Diego. For each patient, three PBx cores from their diagnostic PBx with tumor tissue were selected based on availability of sufficient tissue for genomic analysis. Likewise, RP and LN specimens positive for tumor were retrieved. For 16 patients, a matched diagnostic PBx core specimen was not available. After filtering for specimens that failed microarray quality control, retrospective cohort yielded seven, 22, and 18 tissue specimens from PBx, RP, and LNs for individual patients, respectively. All specimens were rereviewed by an expert uropathologist (A.S). The index tumor was considered as the lesion with the highest Gleason score sampled using a 1.5 mm punch tool. The "index" PBx was defined as the core with the highest Gleason score and highest percentage of tumor involvement. The University of California, San Diego, institutional review board approved the research protocol under which this study was conducted.

\section{Calculation of Decipher}

The expression values for the 22 prespecified biomarkers that constitute Decipher were extracted from the normalized data matrix and entered into the locked random forest algorithm with tuning and weighting parameters defined previously. ${ }^{3}$ The Decipher readout is a continuous risk score between 0 and 1 , with higher scores indicating a greater probability of disease progression or metastasis. ${ }^{3,7,10}$ Decipher was also stratified into low $(<0.45)$, intermediate $(0.45-0.60)$, and high $(>0.60)$ risk groups based on previously developed and validated cut-points. ${ }^{9,14}$

\section{Statistical analysis}

Univariable and multivariable (MVA) logistic regression analyses were used to evaluate the performance of Decipher in predicting LNI in the contemporary cohort. The c-index of the pathologic and Decipher plus pathologic models was estimated by subjecting the model to bootstrapping with 10,000 resamples. Fisher's exact test was used to study the association of clinicopathologic variables between study cohorts. Exact binomial confidence intervals (CIs) were constructed to measure the concordance of Decipher score among matched $\mathrm{PBx}, \mathrm{RP}$, and LN pathologic specimens in the retrospective cohort. Pairwise agreement of Decipher scores in the retrospective cohort was evaluated using BlandAltman plots. ${ }^{15}$ All statistical tests involving biopsy samples were performed after index PBx sample selection unless stated otherwise. In the retrospective cohort, Kaplan-Meier method was used to estimate two endpoints: 1) biochemical recurrence rate, which was defined as a postoperative prostate-specific antigen (PSA) value $>0.2$ on two consecutive measurements; and 2) clinical recurrence rate, which was defined as local, and/or distant recurrence defined by imaging, and/or prostate-bed biopsy. Statistical analyses were performed using the R statistical software (R Foundation for Statistical Computing, Vienna, Austria) considering a statistical significance at $P<0.05$.

\section{Results}

\section{Patient characteristics}

The clinical and pathologic characteristics of patients tested with Decipher in the contemporary cohort are summarized in Table 1. Median age at surgery was 67 years (interquartile range [IQR], 61-71). Median pre-operative PSA was $6.4 \mathrm{ng} / \mathrm{mL}$ (IQR: 4.7-9.6). Overall, 75.5\%, 11.1\%, and $13.3 \%$ of patients had pathologic Gleason score $\leq 7,8$, and $\geq 9$, respectively; $58.9 \%$ of patients harbored pT3 disease; and $55.4 \%$ had positive surgical margins. Fifty-one (2.6\%) patients presented with LNI at RP.

In the retrospective cohort, 22 patients had complete clinical and pathologic characteristics and Decipher RP scores for analysis. A subset of 7 and 18 patients had tissue available 
Table I Patient clinical and pathologic characteristics in the contemporary cohort

\begin{tabular}{ll}
\hline Variables & Total (\%) \\
\hline No patients (\%) & $1,987(100)$ \\
Age, year, median (IQR) & $65(62-69)$ \\
Pre-operative PSA (ng/mL), median (IQR) & $6.4(4.7-9.6)$ \\
Pathologic Gleason score, $\mathrm{n}(\%)$ & \\
$\quad \leq 7$ & $\mathrm{I}, 500(75.5)$ \\
8 & $220(1 \mathrm{I} . \mathrm{I})$ \\
$\geq 9$ & $264(13.3)$ \\
Unknown & $3(0.2)$ \\
Pathologic stage, $\mathrm{n}(\%)$ & \\
$\quad$ T2 & $772(38.9)$ \\
T3a & $780(39.3)$ \\
T3b & $390(19.6)$ \\
T4 & $14(0.7)$ \\
$\quad$ Unknown & $31(\mathrm{I} .6)$ \\
Positive surgical margins, $\mathrm{n}(\%)$ & $\mathrm{I}, 100(55.4)$ \\
Lymph node invasion, $\mathrm{n}(\%)$ & $5 \mathrm{I}(2.6)$ \\
\hline
\end{tabular}

Abbreviations: IQR, interquartile range; PSA, prostate-specific antigen.

from PBx and LN specimens, respectively. Retrospective cohort patients' clinical and pathologic characteristics are summarized in Table 2. Median age at surgery was 60 years (IQR, 57-66). Median pre-operative PSA value was $6.9 \mathrm{ng} / \mathrm{mL}$ (IQR, 4.8-16.1). At biopsy, 91\% had Gleason score $8-10,41 \%$ had clinical stage $\mathrm{T} 2 \mathrm{~b}$ disease, and $90.9 \%$ were classified as high risk by National Comprehensive
Table 2 Patient clinical and pathologic characteristics in the retrospective cohort

\begin{tabular}{ll}
\hline Variables & Total (\%) \\
\hline No patients (\%) & $22(\mathrm{I00})$ \\
Age, year, median (IQR) & $60(57-66)$ \\
Pre-operative PSA (ng/mL), median (IQR) & $6.9(4.8-16 . \mathrm{I})$ \\
Pathologic Gleason score, $\mathrm{n}(\%)$ & \\
$\quad \leq 7$ & $2(9.1)$ \\
8 & $9(40.9)$ \\
$\geq 9$ & $1 \mathrm{I}(50.0)$ \\
Unknown & $0(0)$ \\
Pathologic stage, $\mathrm{n}(\%)$ & \\
$\quad$ T2 & $3(13.6)$ \\
T3a & $8(36.4)$ \\
T3b & $10(45.5)$ \\
$\quad$ T4 & $\mathrm{I}(4.5)$ \\
Positive surgical margins, $\mathrm{n}(\%)$ & $12(54.5)$ \\
Lymph node invasion, $\mathrm{n}(\%)$ & $22(100)$ \\
Follow-up time (censored), mo, median (IQR) & $16(4-35)$ \\
\hline
\end{tabular}

Abbreviations: IQR, interquartile range; mo, months; PSA, prostate-specific antigen; yr, year.

Cancer Network (NCCN) criteria. At RP, $90.9 \%$ of patients had Gleason score 8-10, 81.9\% harbored pT3 disease, and $54.5 \%$ had positive surgical margins. The median follow-up time for this cohort was 16 months (IQR, 4-35). At 5 years post-RP, the estimated biochemical recurrence rate and clinical recurrence rate were $73 \%$ and $24 \%$, respectively (Figure S1). A comparison of the clinical and pathologic

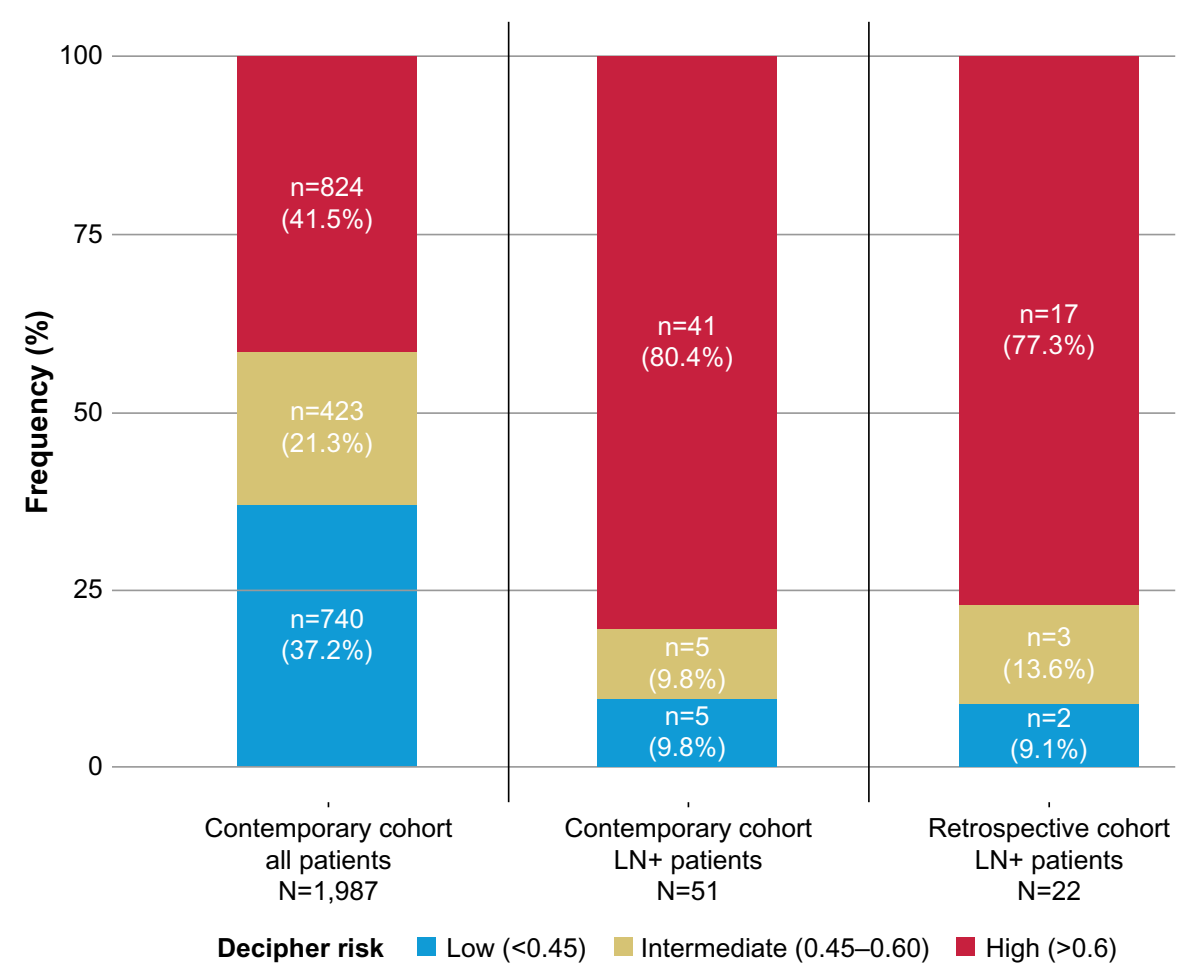

Figure I Bar charts showing frequency of Decipher risk groups in (left) contemporary cohort, (center) LN+ patients of contemporary cohort, and (right) LN+ patients of retrospective cohort from genomic marker assessment in RP specimens.

Abbreviations: LN, lymph node; RP, radical prostatectomy. 
characteristics of the LNI patients in the contemporary and retrospective cohorts did not show any significant difference (all $P>0.1$ ) between the two cohorts (Table S1).

Patients were also stratified using Decipher risk groups (low, intermediate, and high). In the contemporary cohort, $9.8 \%, 9.8 \%$, and $80.4 \%$ of LN positive patients were categorized as Decipher low, intermediate, and high risk, respectively (Figure 1). In the retrospective cohort, we observed a similar distribution with $9.1 \%, 13.6 \%$, and $77.3 \%$ categorized into Decipher low, intermediate, and high risk, respectively. There was no significant difference with respect to Decipher distribution of LN positive patients between the two cohorts $(P>0.1)$.

\section{Evaluation of Decipher for $\mathrm{LNI}$ prediction in the contemporary cohort}

On univariable, Decipher had an odds ratio (OR) of 1.73 (95\% CI, 1.46-2.05, $P<0.001$ ) per 10\% increase in score for predicting the presence of LNI (Table 3). Gleason score
Table 3 Univariable logistic regression analysis of Decipher and pathologic variables for prediction of lymph node invasion in the contemporary cohort

\begin{tabular}{lll}
\hline Variables/endpoint & \multicolumn{2}{l}{ Lymph node invasion } \\
\cline { 2 - 3 } & OR $(\mathbf{9 5} \% \mathrm{CI})$ & P-value \\
\hline Decipher $^{\mathrm{a}}$ & $\mathrm{I} .73(\mathrm{I} .46-2.05)$ & $<0.00 \mathrm{I}$ \\
Pathologic Gleason score 3+3 & ref & $\mathrm{I}$ \\
Pathologic Gleason score 3+4 & $0.78(0.08-7.58)$ & 0.83 \\
Pathologic Gleason score 4+3 & $2(0.24-16.78)$ & 0.52 \\
Pathologic Gleason score 8 & $8.77(\mathrm{I} .18-65.29)$ & 0.03 \\
Pathologic Gleason score $\geq 9$ & $6.0 \mathrm{I}(0.79-45.89)$ & 0.08 \\
Extraprostatic extension & $6.1(2.59-14.35)$ & $<0.00 \mathrm{I}$ \\
Seminal vesicle invasion & $5.74(3.25-10.13)$ & $<0.00 \mathrm{I}$ \\
\hline
\end{tabular}

Note: accipher reported per 0.1 unit increase. A statistical significance at $P<0.05$ was applied.

Abbreviations: $\mathrm{Cl}$, confidence interval; OR, odds ratio; ref, reference group.

8 disease had an OR of 8.77 (95\% CI, 1.18-65.29, $P=0.03)$. Extraprostatic extension (EPE) and seminal vesicle invasion (SVI) also were significant predictors of LNI with OR

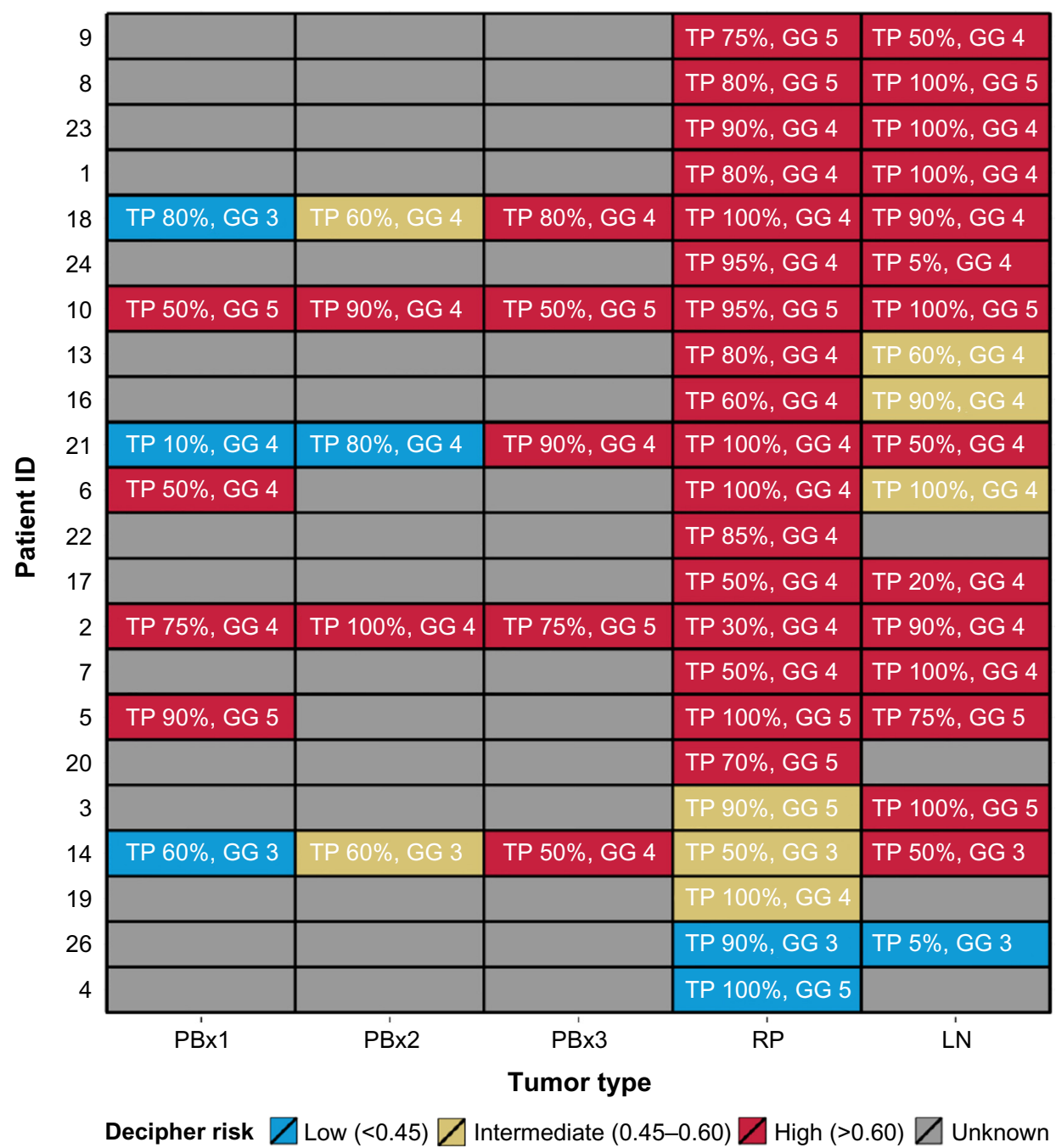

Figure 2 Heat map of Decipher risk groups for all patients in the retrospective cohort.

Abbreviations: GG, highest Gleason grade; LN, lymph node; PBx, prostate biopsy; RP, radical prostatectomy; TP, tumor percentage. 
Table 4 Multivariable logistic regression analysis of Decipher and pathologic variables for prediction of lymph node invasion in the contemporary cohort

\begin{tabular}{lll}
\hline Variables/endpoint & \multicolumn{2}{l}{ Lymph node invasion } \\
\cline { 2 - 3 } & OR (95\% CI) & P-value \\
\hline Decipher $^{\mathrm{a}}$ & I.42 (I.I9-I.7) & $<0.00 \mathrm{I}$ \\
Pathologic Gleason score 3+3 & ref & $\mathrm{I}$ \\
Pathologic Gleason score 3+4 & $0.39(0.04-3.92)$ & 0.43 \\
Pathologic Gleason score 4+3 & $0.56(0.06-4.95)$ & 0.6 \\
Pathologic Gleason score 8 & I.84 (0.23-I4.73) & 0.57 \\
Pathologic Gleason score $\geq 9$ & $0.85(0.1-7.09)$ & 0.88 \\
Extraprostatic extension & $3.48(I .44-8.4 I)$ & $0.0 \mathrm{I}$ \\
Seminal vesicle invasion & $2.73(\mathrm{I} .47-5.08)$ & $<0.00 \mathrm{I}$ \\
\hline
\end{tabular}

Note: ${ }^{a}$ Decipher reported per 0.1 unit increase. A statistical significance at $P<0.05$ was applied.

Abbreviations: $\mathrm{Cl}$, confidence interval; OR, odds ratio; ref, reference group.

of $6.10(95 \% \mathrm{CI}, 2.59-14.35, P<0.001)$ and $5.74(95 \% \mathrm{CI}$, $3.25-10.13, P<0.001)$, respectively. Patient age at RP and pre-operative PSA were not significant predictors of LNI (data not shown). Patient age at RP and pre-operative PSA were not modeled on MVA as these variables were missing for a significant portion of patients.

On MVA, adjusting for pathologic Gleason score, EPE, and SVI Decipher had an OR of 1.42 (95\% CI, 1.19-1.7, $P<0.001)$ per $10 \%$ increase in score for predicting the presence of LNI (Table 4). EPE and SVI also remained significant predictors of LNI on MVA. In contrast, Gleason score 8 disease did not remain significant for predicting LNI after adjusting for Decipher and other pathologic variables. Similar results were observed in univariable and MVA for Decipher risk groups (Tables S2 and S3). On MVA analysis adjusting for pathologic Gleason score, EPE, and SVI, the Decipher high risk group $(>0.6)$ had an OR of $3.23(95 \%$ CI, 1.2-8.73, $P=0.02$ ), similar to the OR of EPE and SVI for predicting the presence of LNI. Finally, discrimination analysis showed that Decipher had a c-index of 0.78 (95\% CI, 0.71-0.84) for prediction of LNI. Combination of Decipher with pathologic variables increased the c-index to 0.85 (95\% CI, 0.73-0.86) from 0.83 (95\% CI, 0.71-0.84) for pathologic model alone (Figure S2).

\section{Concordance of Decipher in pre- and post-RP tissue specimens in the retrospective cohort}

A patient-per-patient pairwise agreement among biopsy cores ( $\leq 3$ cores for each patient with available Decipher scores), $\mathrm{RP}$, and LN specimens is shown in Figure 2. Among all available PBx specimens, $65 \%$ were categorized as Decipher high risk, whereas $100 \%$ of selected PBx specimens (highest sampled Gleason grade and percentage of tumor involvement),
77\% RP, and 78\% LN specimens had high Decipher scores. Bland-Altman plots, which examined patient-per-patient agreement, showed a good overall concordance for all three compared tissue specimens (Figure S3).

Finally, we examined Decipher agreement in pairwise comparisons between the following 1) PBx and RP specimens, 2) PBx and LN specimens, and 3) RP and LN specimens when PBx selection was performed (Table 5). Without selection of PBx specimens (ie, taking the average Decipher score for all cores), the overall concordance with RP Decipher risk groups was $71 \%$, which increased to $86 \%$ concordance when the selected PBx core (ie, with the highest sampled Gleason grade and percentage of tumor involvement) was compared to RP Decipher. The concordance between PBx and $\mathrm{LN}$ was $43 \%$ for the average of all $\mathrm{PBx}$ specimens in each patient and similarly increased to $86 \%$ when comparing only the PBx with highest sampled Gleason grade and percentage of tumor involvement. The concordance of RP and LN Decipher scores was $72 \%$.

\section{Discussion}

Here, we evaluated the performance of Decipher scores on RP specimens for prediction of LNI in a contemporary cohort and then in an exploratory analysis of a small retrospective cohort determined the agreement of Decipher scores among pre- and post-operative tissue specimens, including LN with tumor involvement. Our results show that Decipher is a strong predictor of LNI in a contemporary cohort of nearly 2,000 patients. In a retrospective cohort, with similar characteristics to the LNI patients of a contemporary RP cohort, we observed high concordance between Decipher scores in PBx and both $\mathrm{RP}$ and LN specimens of individual patients. The caveat is that this is only true when the PBx sampled with highest Gleason grade and percentage of tumor involvement is selected.

Our study has several limitations. In the contemporary cohort: the lack of information on pre-operative variables, extended pelvic lymph node dissection (ePLND) status, and

Table 5 Concordance of Decipher scores across tumor types using various selection methods for biopsy samples with multiple tumors in the retrospective cohort

\begin{tabular}{lll}
\hline $\begin{array}{l}\text { Pairwise } \\
\text { comparison }\end{array}$ & $\begin{array}{l}\text { Overall } \\
\text { concordance }\end{array}$ & $\begin{array}{l}\text { Concordance/PBx } \\
\text { selected based on highest } \\
\text { TP and dominant GG }\end{array}$ \\
\hline PBx-RP (\%) & $71(29-96)^{\mathrm{a}}$ & $86(42-100)$ \\
PBx-LN (\%) & $43(10-82)^{\mathrm{a}}$ & $86(42-100)$ \\
RP-LN (\%) & $72(47-90)$ & $72(47-90)$ \\
\hline
\end{tabular}

Note: ${ }^{\text {an }}$ case of a tie, sample with highest tumor percent and dominant Gleason grade was selected.

Abbreviations: GG, highest Gleason grade; LN, lymph node; PBx, prostate biopsy; RP, radical prostatectomy; TP, tumor percentage. 
number of $\mathrm{LN}$ retrieved for all patients. In the retrospective cohort: the small sample size of the matched PBx specimens and the lack of a matched set of control patients (ie, without LNI) to determine the discrimination performance of the genomic marker expression in PBx for predicting LNI. We aimed to address these issues in part by considering a large contemporary cohort that included both LN negative and positive patients in order to show the discrimination of the genomic marker for predicting the presence of LNI. However, further validation of Decipher on larger PBx cohorts is warranted to confirm the results of the current study.

\section{Conclusion}

In summary, in our study, Decipher was highly predictive of LNI from analysis of RP specimens in a large contemporary cohort. Improved post-operative LNI staging may be useful for selection of patients for adjuvant hormonal or whole pelvic irradiation. Decipher scores were also highly concordant between pre- and post-operative specimens. If validated in a larger cohort of $\mathrm{PBx}$ specimens, Decipher may improve pre-operative staging, which is useful for optimal selection of patients for neoadjuvant therapy, primary radiotherapy as well as RP with ePLND.

\section{Acknowledgments}

CJK received an unrestricted research grant from GenomeDx to support the costs of sample acquisition and data generation. FA is a consultant and $\mathrm{KY}, \mathrm{ZH}$, LLCL, HS, MA, and ED are employees of GenomeDx Biosciences.

\section{Disclosure}

The authors report no conflicts of interest in this work.

\section{References}

1. Boström PJ, Bjartell AS, Catto JWF, et al. Genomic predictors of outcome in prostate cancer. Eur Urol. 2015;68(6):1033-1044. doi:10.1016/j. eururo.2015.04.008.

2. Ross AE, D'Amico AV, Freedland SJ. Which, when and why? Rational use of tissue-based molecular testing in localized prostate cancer. Prostate Cancer Prostatic Dis. Epub 2015 Jun 30. doi:10.1038/pcan.2015.31.
3. Erho N, Crisan A, Vergara IA, et al. Discovery and validation of a prostate cancer genomic classifier that predicts early metastasis following radical prostatectomy. PLoS One. 2013;8(6):e66855. doi:10.1371/ journal.pone.0066855.

4. Karnes RJ, Bergstralh EJ, Davicioni E, et al. Validation of a genomic classifier that predicts metastasis following radical prostatectomy in an at risk patient population. J Urol. 2013;190(6):2047-2053. doi:10.1016/j. juro.2013.06.017.

5. Den RB, Feng FY, Showalter TN, et al. Genomic prostate cancer classifier predicts biochemical failure and metastases in patients after postoperative radiation therapy. Int J Radiat Oncol Biol Phys. 2014;89(5):1038-1046. doi:10.1016/j.ijrobp.2014.04.052.

6. Ross AE, Feng FY, Ghadessi M, et al. A genomic classifier predicting metastatic disease progression in men with biochemical recurrence after prostatectomy. Prostate Cancer Prostatic Dis. 2014;17(1):64-69. doi:10.1038/pcan.2013.49.

7. Klein EA, Yousefi K, Haddad Z, et al. A genomic classifier improves prediction of metastatic disease within 5 years after surgery in nodenegative high-risk prostate cancer patients managed by radical prostatectomy without adjuvant therapy. Eur Urol. 2015;67(4):778-786. doi:10.1016/j.eururo.2014.10.036.

8. Den RB, Yousefi K, Trabulsi EJ, et al. Genomic classifier identifies men with adverse pathology after radical prostatectomy who benefit from adjuvant radiation therapy. J Clin Oncol. 2015;33(8):944-951. doi:10.1200/JCO.2014.59.0026.

9. Ross AE, Johnson MH, Yousefi K, et al. Tissue-based genomics augments post-prostatectomy risk stratification in a natural history cohort of intermediate- and high-risk men. Eur Urol. 2016;69(1):157-165. doi:10.1016/j.eururo.2015.05.042.

10. Klein EA, Haddad Z, Yousefi K, et al. Decipher genomic classifier measured on prostate biopsy predicts metastasis risk. Urology. Epub 2016 Jan 22. doi:10.1016/j.urology.2016.01.012.

11. Freedland SJ, Choeurng V, Howard L, et al. Utilization of a genomic classifier for prediction of metastasis following salvage radiation therapy after radical prostatectomy. Eur Urol. Epub 2016 Jan 21. doi:10.1016/ j.eururo.2016.01.008.

12. Yamoah K, Johnson MH, Choeurng V, et al. Novel biomarker signature that may predict aggressive disease in African American men with prostate cancer. J Clin Oncol. 2015;33(25):2789-2796. doi:10.1200/ JCO.2014.59.8912.

13. Glass AG, Leo MC, Haddad Z, et al. Validation of a genomic classifier for predicting post-prostatectomy recurrence in a communitybased healthcare setting. J Urol. Epub 2015 Nov 25. doi:10.1016/j. juro.2015.11.044.

14. Choeurng V, Luo B, Yousefi K, et al. Re-calibration of genomic risk prediction models in prostate cancer to improve individual-level predictions. In: Joint Statistical Meeting; August 8-13, 2015; Seattle, Washington.

15. Bland JM, Altman DG. Statistical methods for assessing agreement between two methods of clinical measurement. Lancet. 1986;1(8476):307-310. 


\section{Supplementary materials}

Table SI Comparison of LNI patient characteristics from retrospective and contemporary cohorts

\begin{tabular}{|c|c|c|c|}
\hline Variables & $\begin{array}{l}\text { Retrospective } \\
\text { cohort } \mathrm{N}=\mathbf{2 2}\end{array}$ & $\begin{array}{l}\text { Contemporary } \\
\text { cohort LN } \\
\mathrm{N}=5 \text { I }\end{array}$ & $P$-value* \\
\hline \multicolumn{4}{|c|}{ Patient characteristics } \\
\hline Age, yr, median (IQR) & $60(57-66)$ & $65(64-68)$ & \\
\hline $\begin{array}{l}\text { Pre-operative PSA } \\
(\mathrm{ng} / \mathrm{mL}) \text {, median (IQR) }\end{array}$ & $6.9(4.8-16.1)$ & $7.58(5.1-11.8)$ & \\
\hline $\begin{array}{l}\text { Pathologic Gleason } \\
\text { score, } n(\%)\end{array}$ & & & $>0.1$ \\
\hline$\leq 7$ & $2(9.1)$ & $10(19.6)$ & \\
\hline 8 & $9(40.9)$ & $25(49.0)$ & \\
\hline$\geq 9$ & II (50.0) & I5 (29.4) & \\
\hline Unknown & $0(0.0)$ & I (2.0) & \\
\hline Pathologic stage, n (\%) & & & $>0.1$ \\
\hline $\mathrm{T} 2$ & $3(13.6)$ & $5(9.8)$ & \\
\hline T3a & $8(36.4)$ & $16(31.4)$ & \\
\hline $\mathrm{T} 3 \mathrm{~b}$ & $10(45.5)$ & $29(56.9)$ & \\
\hline $\mathrm{T} 4$ & I (4.5) & I (2.0) & \\
\hline
\end{tabular}

Note: *Fisher's exact test. A statistical significance at $P<0.05$ was applied.

Abbreviations: IQR, interquartile range; LN, lymph node; LNI, lymph node invasion; PSA, prostate-specific antigen; yr, year.

Table S2 Univariable logistic regression analysis of categorical Decipher and pathologic variables for prediction of lymph node invasion in the contemporary cohort

\begin{tabular}{lll}
\hline Variables/endpoint & \multicolumn{2}{l}{ Lymph node invasion } \\
\cline { 2 - 3 } & OR (95\% CI) & P-value \\
\hline Decipher low risk & ref & I \\
Decipher intermediate risk & I.76 (0.5I-6.II) & 0.37 \\
Decipher high risk & $7.7(3.03-19.58)$ & $<0.00$ I \\
Pathologic Gleason score 3+3 & ref & I \\
Pathologic Gleason score 3+4 & $0.78(0.08-7.58)$ & 0.83 \\
Pathologic Gleason score 4+3 & $2(0.24-16.78)$ & 0.52 \\
Pathologic Gleason score 8 & $8.77(1.18-65.29)$ & 0.03 \\
Pathologic Gleason score $\geq 9$ & 6.0 I (0.79-45.89) & 0.08 \\
Extraprostatic extension & $6.1(2.59-14.35)$ & $<0.00$ I \\
Seminal vesicle invasion & $5.74(3.25-10.13)$ & $<0.00$ I
\end{tabular}

Abbreviations: $\mathrm{Cl}$, confidence interval; OR, odds ratio; ref, reference group. Note: A statistical significance at $P<0.05$ was applied.
Table S3 Multivariable logistic regression analysis of categorical Decipher and pathologic variables for prediction of lymph node invasion in the contemporary cohort

\begin{tabular}{lll}
\hline Variables/endpoint & \multicolumn{2}{l}{ Lymph node invasion } \\
\cline { 2 - 3 } & OR (95\% CI) & P-value \\
\hline Decipher low risk & ref & I \\
Decipher intermediate risk & I.23 (0.35-4.38) & 0.75 \\
Decipher high risk & $3.23($ I.2-8.73) & 0.02 \\
Pathologic Gleason score 3+3 & ref & I \\
Pathologic Gleason score 3+4 & 0.4 I $(0.04-4.12)$ & 0.45 \\
Pathologic Gleason score 4+3 & $0.64(0.07-5.72)$ & 0.69 \\
Pathologic Gleason score 8 & $2.46(0.31-19.57)$ & 0.4 \\
Pathologic Gleason score $\geq 9$ & I.I (0.13-9.25) & 0.93 \\
Extraprostatic extension & $3.93(I .63-9.46)$ & $<0.00$ I \\
Seminal vesicle invasion & $3.09(I .67-5.73)$ & $<0.00$ I \\
\hline
\end{tabular}

Abbreviations: $\mathrm{Cl}$, confidence interval; OR, odds ratio; ref, reference group Note: A statistical significance at $P<0.05$ was applied. 
A

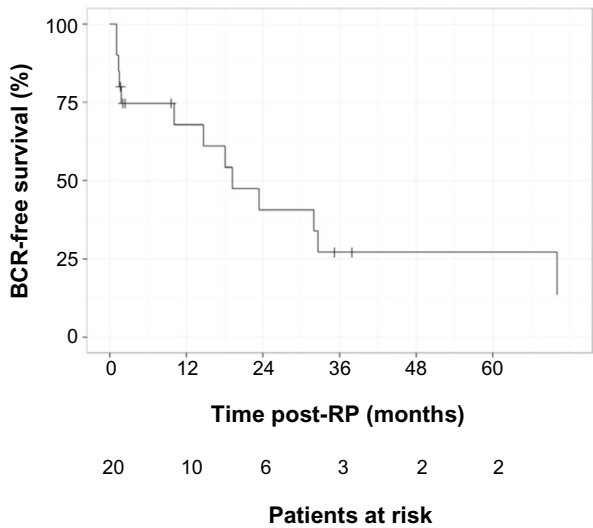

B

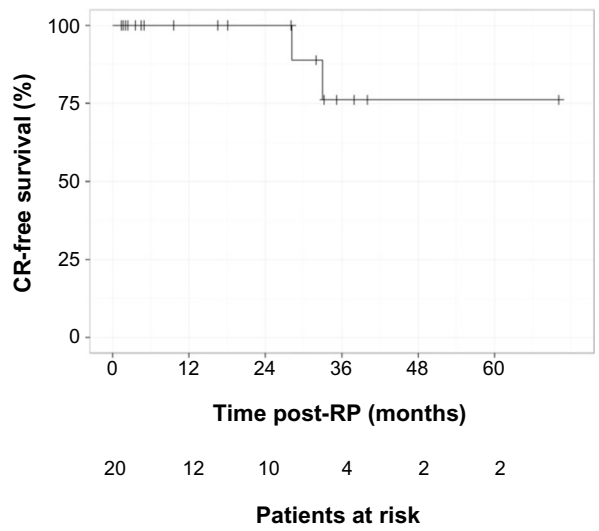

Figure SI Kaplan-Meier estimates of survival-free (A) BCR and (B) CR in retrospective cohort. Abbreviations: $B C R$, biochemical recurrence; $C R$, clinical recurrence; RP, radical prostatectomy.

\section{Lymph node invasion endpoint}

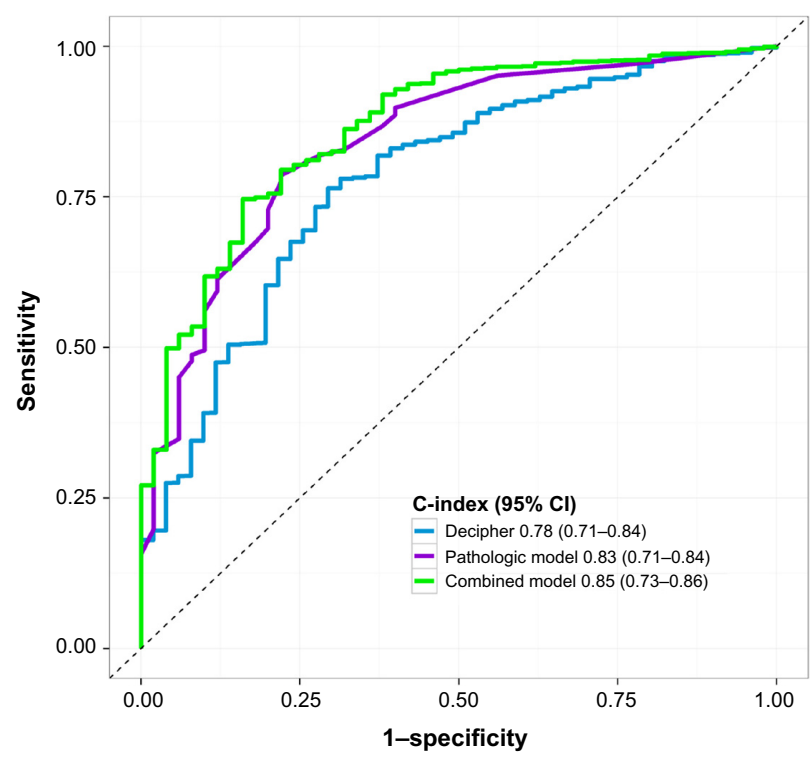

Figure S2 ROC curves of Decipher and pathologic variables in the contemporary cohort.

Abbreviation: $\mathrm{Cl}$, confidence interval.

Research and Reports in Urology

\section{Publish your work in this journal}

Research and Reports in Urology is an international, peer-reviewed, open access journal publishing original research, reports, editorials, reviews and commentaries on all aspects of adult and pediatric urology in the clinic and laboratory including the following topics: Pathology, pathophysiology of urological disease; Investigation and treatment of

\section{A}

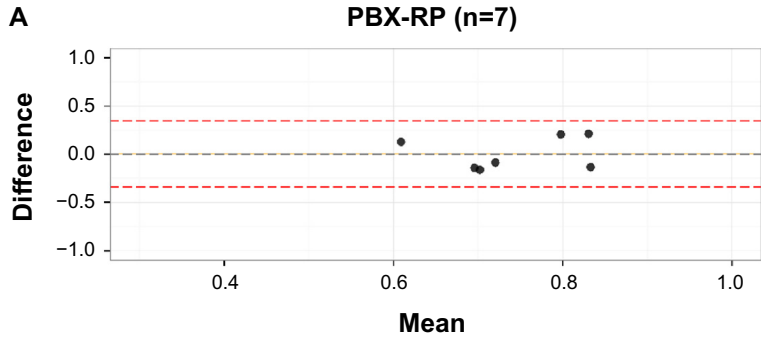

B

PBX-LN (n=7)

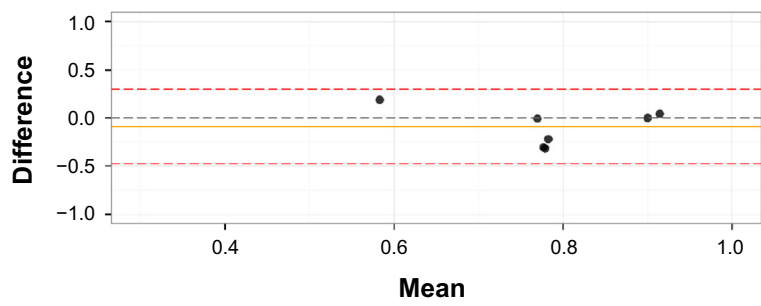

C

RP-LN ( $n=18)$

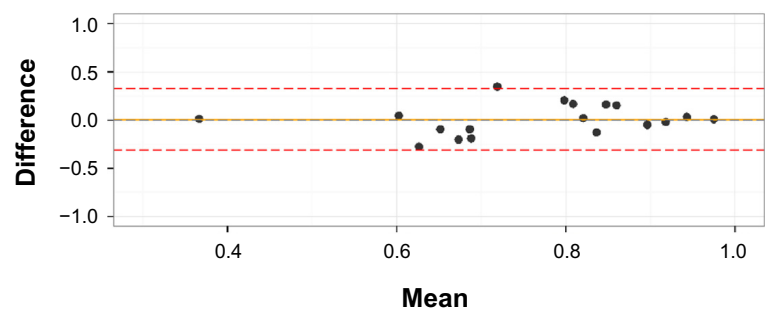

Figure S3 Pairwise Bland-Altman plots to evaluate agreement of Decipher scores between (A) PBx and RP, (B) PBx and LNs, and (C) RP and LNs in retrospective cohort.

Abbreviations: PBx, prostate biopsy; RP, radical prostatectomy; LN, lymph node.

\section{Dovepress}

urological disease; Pharmacology of drugs used for the treatment of urological disease. The manuscript management system is completely online and includes a very quick and fair peer-review system, which is all easy to use. Visit http://www.dovepress.com/testimonials.php to read real quotes from published authors. 